Original article:

\title{
Life-orientation, Subjective Well-being and Social Support as Predictors of Quality of Life in Patients with End Stage Renal Disease \\ Masood $A^{1}$, Kamran $F^{2}$, Rashid $S^{3}$, Mazahir $S^{4}$
}

\begin{abstract}
$\underline{\text { Abstract }}$
Background: Psychosocial experiences such as life-orientation, subjective well-being and social support are punitive in determining the health related quality of life of patients in end stage of Chronic Renal Disease; also termed as End Stage Renal Disease (ESRD). Objectives: to investigate the phenomenon of life-orientation, subjective well-being, social support and perceived health related quality of life in patients with end stage renal disease. ESRD patients' life orientation, social support and subjective well-being are significant predictors of their perceived quality of life that further determines their disease management and health status. Materials and Methods: This research has been laid out through cross sectional survey research design. The data was collected between the time span of Jan, 2016 to June, 2016. The sample comprised of 200 respondents from both gender, equally distributed within the age range of 50 to 60 years, going through last stage of ESRD and relying on dialysis from at least past one year or more. Indigenously translated WHO QoL, Subjective Wellbeing Scale, multidimensional Social Support Scale, Life Orientation Scale and a demographic information sheet was used to collect the data. Results: The results revealed that life orientation, social support and subjective well-being significantly and positively predicted the health related quality of life; greater social support and higher levels of subjective wellbeing after controlling for the effects of age, gender, income and education were found when the patients 'carried optimistic and positive life-orientation. Conclusion: The current research findings therefore incriminate preemptive direction in understanding the phenomenon of life-orientation, social support, subjective wellbeing and health related quality of life in patients with last stage ESRD. This further embarks onto highlighting the insightful guidelines for health and clinical psychologists in devising management interventions, targeting the increased subjective well-being, and promotion of optimistic life-orientation in order to facilitate health related quality of life in the patients with end stage renal disease.
\end{abstract}

Keywords: end stage renal disease; impact of disease; Life-orientation; social support, quality of life; Subjective well-being

Bangladesh Journal of Medical Science Vol. 16 No. 03 July'17. Page : 346-353

\section{Introduction}

End-stage renal disease (ESRD) is the synonymous term to chronic kidney disease that has been used when patients with kidney failure diseased state are considered. ESRD is a challenging, exigent lifethreatening state that puts a patient's life at stake as this leads to defected kidneys with allied health compromised conditions. Survival of such patients is pivotally dependent on such serious management measures such as dialysis or renal transplants if patients manage to find a donor, perfectly matching their tissue sample. ${ }^{1,2}$ Treatment options also

1. Afsheen Masood, Assistant Professor, Institute of Applied Psychology, University of the Punjab, Quaid e Azam Campus, Lahore

2. Fatima Kamran, Assistant Professor, Institute of Applied Psychology, University of the Punjab, Quaid e Azam Campus, Lahore

3. Sumaira Rashid, Department of Applied Psychology, Kinnaird College for Women, Lahore

4. Shama Mazahir, Internee Clinical Psychologist, University of the Punjab, Lahore

Department of Applied Psychology, University of the Punjab, Quaid-e-Azam Campus, Lahore, Pakistan.

Correspondence to: Dr. Afsheen Masood, Assistant Professor, Institute of Applied Psychology, University of the Punjab, Quaid e Azam Campus, Lahore, Pakistan. drafsheenmasood@gmail.com 
extend limited choices to such patients as not every management is feasible with all such patients. Furthermore this has been found that ESRD comes with wide array of complication and co morbid diseased states due to which they incur irreparable loss on psychological health of such clients. It is clinically documented that the health conditions of the patients with ESRD is worse than average populations; this happens to be the primary reason that this diseased population is assessed for health related quality of life (HRQOL). ${ }^{3,4}$

Patients in End Stage Renal disease have compromising health status due to the taxing nature of the management that they have to adopt during dialysis modality procedures. There have been multiple identified factors that could contribute to a patients' health related quality of life and prominent among them being the social support, subjective wellbeing, and life orientation that seem to contribute pivotally towards the management of the state of dialysis. ${ }^{5}$ These factors may also improve or mar the perceived health related quality of life of all such patients. Optimism and Health related quality of life are somehow widely neglected domains in research though in clinical observations, these factors have been found to play crucial and determining role. ${ }^{6}$ The end stage renal disease has been assumed to be fatalistic for many decades until recently the facilities of dialysis became much more common and affordable in Pakistan from past three decades. Therefore the improved health related quality of life has been raised in an attempt to understand the intricate interplay of various factors that lead to the determination of health related quality of life. ${ }^{7}$ It has been reported in clinics that fewer patients enjoy better quality of life than some others and this raises the potential contribution of health psychologist to outline all such factors that contribute to such patient's well-being. The service care provision for Renal Transplants patients is much better in Pakistan as far as the big cities are concerned. Dialysis outcomes relate complications are also recorded as fewer when there is better orientation of the patients towards life, and when there is adequate social support availed by the patients. That is why now health related quality of life is measured from patients' subjective perspective rather than objective view. ${ }^{8,9}$

Social support is another variable that has gained wide importance in empirical domain for determining better quality of life for patients with end stage renal disease. There have been number of investigations that have established the sound link between perceived social support and quality of life in patients with end stage renal disease. ${ }^{10}$ Social supports carried two different dimensions as being the confidant based support which means that patients feel the presence of some significant figure in their life due to which they have better quality of life and sense of better subjective well-being. The second dimension illustrates that there are affective channels available to an individual due to whom there are ample cathartic activities available to ESRD patients due to which their perceived well-being increases. ${ }^{11}$ Untas et al. examined this relationship on large sample of around thirty two thousand patients and revealed that there were diverse perception levels of available social support. This diversification of social support also varied systematically across different ethnic groups. This study was large scaled and multicenter and multi cohorts based. The findings by him clearly revealed that patients in ESRD who felt socially isolated, happen to report poorer quality of life and greater distress. ${ }^{12,13}$ They were communicated by their families as source of strain and burden and they carried varied patterns of symptoms severity. This establishes the link between the health related quality of life of patients in grave diseases with the psychological states and health. In health care setting this has been increasingly recognized that psychological states if properly managed can lead to optimistically better physical health of the patients in grave diseases' conditions. Thus efficacy of cost effective analysis of physical health settings also demand the utilization of psychological management and emotions-handling in order to promote wellbeing in such patients. Social support acts as effective means of coping. There are varied coping responses that patients in ESRD adopt and social support surges as most prominent among them. This involves physical and social support extended by others and this has been well-documented that this improves coping in case of chronic illnesses such as cancer. There are improved outcomes and improved survival in ESRD when social support gets conjoined with optimism. ${ }^{14,15}$

There has been tremendous surge in empirical data pertaining to Quality of Life of patients in various chronic diseases. There has been evidence that influence of an individual's life orientation, especially optimism and satisfaction has been shown to predict the perceived QoL. Studies such as by Kivimakis' have shown that an optimistic style towards life may lessen the plausible risks of health problems. This has been widely shown that optimistic people tend to 
recover more rapidly whenever they confront some arduous situation in life. People with optimistic tendency harbor brighter expectations due to which they maintain their energies and experience greater expectation and contentment in life that happens to inflate their physical well-being. ${ }^{16}$ A comparative study by Singh et.al. On ESRD patients waiting for renal transplant and those not waiting for renal transplant revealed that optimism and life satisfaction was higher among non-waiting group and they reported better well-being. Lin, Chiang and Lieu also showed in their investigation that optimism acts as significant factor of life satisfaction in patients with chronic kidney disease state. Numerous studies have shown that optimism is likely to be positively associated with life satisfaction. Optimism is found to indicate better management with ESRD treatment options. ${ }^{17} \mathrm{McClellan}$ et al. ${ }^{18}$ measured perceived social support and showed better coping with catastrophic treatment outcomes.

Life-orientation has been empirically investigated hardly few decades back as Positive psychology in health settings implied its understandings and Optimism emerged as significant construct in it. Optimism vs. pessimism as generally termed as life-orientation imply a generalized expectancy, that an individual may experience in the form of good outcomes in life, attitude or world view to interpret past or present events in a positive manner. There are wide individual differences in the levels of life-orientations and it determines largely the management of distress in health stake conditions. This has been observed by clinicians that expectancy levels broadly vary in magnitude and nature and may lead to predict the behavioural and health related outcomes. This has been stated that in cardiac patients, this has led to perseverance at the wake of odds, control over disease prone conditions and striving towards betterment. In developing countries, especially in Pakistan, the patients with ESRD are increasing at an alarming rate. ${ }^{19,20}$ There has been scanty research that has explored the positive dimensions of growth in adversity when it comes to kidney failure. Thus it is anticipated that findings from such studies can enable the health counsellors understand factors leading to better well-being and quality of life of patients with CKD or renal failure. This sort of tertiary care can prove beneficial for the patients with renal failure. Furthermore better clinical insight for counselling programs can be devised after determining the interlinking of the study variables. In the light of these objectives, it is hypothesized that patients' life-orientation and subjective well-being is likely to predict the perceived health related quality of life of patients with renal failure. Thus, the main aim of the present study was to find out if life-orientation, specifically optimism social support and subjective well-being could predict recipients' perceptions of quality of life. This has been hypothesized that life-orientation, subjective well-being and social support are likely to emerge as significant predictors of perceived health related quality of life in patients with end stage renal disease. ${ }^{21}$

\section{Methodology}

The research has been laid out to explore the phenomenon of life-orientation, subjective wellbeing and perceived health related quality of life in a non-probability purposive sampling strategy based sample. The sample comprised of $\mathrm{N}=200$ patients with stage 5 renal failure, sample size determination was achieved through $\mathrm{G}$ Power factor formula. The patients who were going through different modes of dialysis from past six months to one year or more were selected through purposive sampling strategy. The age of participants ranged between 50 to 60 years. Mean age of the participants was 53.11 years while $\mathrm{SD}=7.32$. The sample was recruited from Dialysis units' functional at public and private sectors of Lahore. The patients reporting any psychiatric co morbid states or the ones having clinically significant anxiety and depression were eliminated from the finally selected sample. Patients were accessed when they came for dialysis or they turned up for follow up to hospitals from diverse parts of Punjab. Written informed consent was obtained from each patient after giving them comprehensive briefing about the nature and purpose of the research. The patients were clarified about the goal of the research and were ensured about the anonymity and confidentiality concerns. For the study, standardized questionnaires of Life-orientation, Subjective well-being Scale and Perceived Health related Quality of Life Scales were used.

\section{Measures}

A set of measures were used in this investigation to assess the study constructs. The foremost being Health related Quality of Life (HRQL). This carried total 30 items. Its accumulative scores were entertained for the current study. The worst quality of life was indicated by the lowest scores while maximal functioning was shown by score of 100 . Second measure was known as Social Support Scale by Duke-UNC-11. This has been termed as functional social support questionnaire and it carries 11 items. It 
has two subscales, regarded as Confidant support and affective support. The rating is done on the measure of 5 to 1 wherein 5 indicates the much less than trends and 1 represents as 1 . The western findings reveal its psychometric properties to be quite high. Third measure was Subjective Well-being Scale by Diener. It is known as global satisfaction measure. It is scored on a 7 point scale wherein strongly disagree denoted by 1 while strongly agree is shown as being 7. Its imputed stability factor in its psychometric oriented investigations has been 0.90. Another significant instrument in this investigation had been Life-Orientation Scale-Revised. This scale has 10 -items that measure optimism versus pessimism. In constitution, this instrument carries three items that assess optimism and three items measure pessimism whereas remaining items work as fillers. The scoring is from 4 to 0 where 4 shows strongly agree while 0 shows strongly disagree. LOT was used in its revised recent short form as this carries significantly higher reliability than the earlier versions.

Sociodemographic and clinical data was also obtained for all the respondents. A self adminsitered instrument was devised that comprehensivly sought information about age, gender, education etc. In a pilot study, all standardized measures were translated through forward and backward translation methods, followed by equivalence determination and validated before final data collection administration and the derived Cronbach's Alpha reliability for all of the measures was significantly higher. Demographic Questionnaire was also employed that contained information about age, mother's education, socio demographic characteristics, health history and family income. Each participant was administered the instruments individually by the researcher; the average time consumed involved 35 minutes. The respondents were cooperative enough and only $3 \%$ refused to be a part of the data collection process; thus ensuring significantly higher response rate of the participants. The demographic information was carefully recorded. The data was analysed through SPSS version 24.00 and SEM. Regression analyses were performed in order to establish the predictive role of life-orientation and subjective well-being in determining the subjective well-being and perceived quality of life in patients with end stage renal failure.

\section{Ethical Considerations}

All respondents were accessed after seeking permission from the dialysis institutes and nephrology clinics after the administration granted permission for data collection. Written informed consent Performa were filled in by all the participants and they were ensued about the confidentiality and anonymity of the data. They were informed about the goal of the research and they were assured that their information would only be used for academic purposes. They were satisfied for all their queries and their right to withdraw from any phase of the research, the moment they felt uncomfortable, was clarified to them. The voluntary participation of the participants was also ensured.

\section{$\underline{\text { Results }}$}

Out of total 200 patients, $48 \%$ belonged to higher income group, 25 from middle income group and 27 $\%$ from lower income group. The sample was equally distributed across the two gender groups. The mean age for women in the current sample was $52.13 \pm 1.21$ while for men it was 56.21 \pm 4.01 .

Table 1:Demographic details are presented in table $1(n=200)$

\begin{tabular}{|c|c|c|}
\hline Demographics & $\begin{array}{c}\text { Hemodialysis } \\
\text { Dialysis }\end{array}$ & $\begin{array}{c}\text { Peritoneal } \\
\text { Dialysis }\end{array}$ \\
\hline Patients (n) & 100 & 100 \\
\hline Gender & $50(25 \%)$ & $50(25 \%)$ \\
\hline Men & $50(25 \%)$ & $50(25 \%)$ \\
\hline Women & $50(25 \%)$ & $25(13.5 \%)$ \\
\hline Education & $150(25 \%)$ & $25(13.5 \%)$ \\
\hline $\begin{array}{c}\text { College and University } \\
\text { education }\end{array}$ &
\end{tabular}

Table 2: Mean, SD and Reliability Coefficients of the Study Variables $(n=200)$

\begin{tabular}{|l|c|c|c|}
\hline \multicolumn{1}{|c|}{ Variables } & Mean & SD & $\alpha$ \\
\hline $\begin{array}{l}\text { LIFE-ORIENTATION } \\
\text { SCALE }\end{array}$ & & & \\
\hline Optimism Scale & 43.12 & 3.31 & .79 \\
\hline Pessimism Scale & 41.02 & 5.02 & .84 \\
\hline QUALITY OF LIFE SCALE & & & .85 \\
\hline Psychosocial & 41.07 & 4.11 & .69 \\
\hline Physical Health (PCS)* & 22.02 & 6.02 & .76 \\
\hline Mental Health (MCS)** & 18.91 & 4.32 & .78 \\
\hline SUBJECTIVE WELL-BEING & 34.56 & 2.03 & .77 \\
\hline SOCIAL SUPPORT SCALE & 76.56 & 13.21 & .84 \\
\hline Confidant Support & 34.56 & 7.56 & .82 \\
\hline Affective Support & 43.32 & 5.43 & .88 \\
\hline
\end{tabular}

*PCS = physical component summary; $* * \mathrm{MCS}=$ mental component summary. 
Table-3:Relationship in major Study variables

\begin{tabular}{|c|c|c|c|c|c|c|c|c|c|c|}
\hline & Variables & 1 & 2 & 3 & 4 & 5 & 6 & 7 & 8 & 9 \\
\hline $\begin{array}{l}1 . \\
\text { scale-C }\end{array}$ & $\begin{array}{l}\text { Life-orientation } \\
\text { ptimism }\end{array}$ & & $.72 * *$ & $.66^{* *}$ & $.06^{* *}$ & -.07 & $.78 * *$ & $.78 * *$ & $.65 * *$ & .34 \\
\hline 2. & Social support scale & & & .58 & $.67^{*}$ & -.56 & $.78 * *$ & $.76^{* *}$ & $.56 * *$ & $.43^{*}$ \\
\hline 3. & Confidant Support & & & & $.45^{*}$ & $.76^{* *}$ & $.76^{* *}$ & $.65^{* *}$ & $.62 *$ & .34 \\
\hline 4. & Affective Support & & & & .34 & .54 & $.45^{*}$ & $.56^{*}$ & .45 & .32 \\
\hline $\begin{array}{l}5 . \\
\text { being }\end{array}$ & Subjective Well- & & & & & $-.67 * *$ & $.65^{* *}$ & $.54^{*}$ & $.45^{*}$ & $.54 * *$ \\
\hline 6. & Quality of Life & & & & & & $66^{* *}$ & $.34 * *$ & $.56^{*}$ & $.45^{*}$ \\
\hline 7. & Physical health & & & & & & & $.72 *$ & $\begin{array}{c}-. \\
-.43 *\end{array}$ & $.32 *$ \\
\hline 8. & Mental health & & & & & & & & $.63^{*}$ & $.54 * *$ \\
\hline 9. & Disease severity & & & & & & & & & \\
\hline
\end{tabular}

Note. ${ }^{* * \mathrm{P}<0.001 ;} * \mathrm{P}<0.05$

Table-4:Life-Orientation, Subjective Well-being and Social Support as Predictor of Quality of Life

\begin{tabular}{|c|c|c|c|c|c|}
\hline Predictors & $\mathbf{R}^{2}$ & $\mathbf{D R}^{2}$ & $\operatorname{Adj}^{2}$ & $\mathbf{F}$ & Final $\mathbf{B}$ \\
\hline 1. Duration of disease & 0.74 & 0.32 & 0.41 & 3.22 & 0.302 \\
\hline 2. Social Support & 0.46 & 0.31 & 0.35 & 4.11 & 0.321 \\
\hline 3. Subjective well-being & 0.25 & 0.91 & 0.51 & 8.71 & 0.213 \\
\hline 4. Life-orientation & 0.47 & 0.43 & 0.52 & 6.21 & 0.121 \\
\hline
\end{tabular}

$\mathrm{P}<0.01$; significant values given in bold

Table-5: Linear regression for determining the social support and life-orientation as the predictors of Quality of Life: $\mathrm{R}^{2}$ values and standardized $\beta$-coefficients in multiple linear regressions for each WHOQOL-BREF and Life-Orientation Test-R LOT domains (model 2)

\begin{tabular}{|c|c|c|c|c|}
\hline Significant predictor & Beta & $\mathbf{F}$ & $\mathbf{R}^{2}$ & Pvalue \\
\hline $\begin{array}{l}\text { Physical Health } \\
\text { Duration of dialysis }\end{array}$ & +0.12 & 2.15 & 0.076 & 0.01 \\
\hline Income & +0.23 & 4.40 & 0.073 & 0.02 \\
\hline Co-morbidities no. & -0.21 & 3.01 & 0.23 & 0.21 \\
\hline Employment status & -0.30 & 3.01 & 0.054 & 0.27 \\
\hline \multicolumn{5}{|l|}{ Psychological health } \\
\hline Optimism-LOT & +.761 & 3.123 & 0.17 & 0.03 \\
\hline Dialysis duration & +0.131 & 4.123 & 0.11 & 0.01 \\
\hline Education status & +0.220 & 0.302 & .43 & 0.02 \\
\hline Gender & -0.233 & 3.221 & 0.34 & 0.20 \\
\hline Income & +0.232 & 3.16 & 0.12 & 0.11 \\
\hline \multicolumn{5}{|l|}{ Social functioning } \\
\hline \multicolumn{5}{|c|}{ In this domain, there is no significant predictor. } \\
\hline \multicolumn{5}{|c|}{\begin{tabular}{|l|l|} 
Environmental health & \\
\end{tabular}} \\
\hline Albumin & +0.120 & 9.120 & 0.21 & 0.12 \\
\hline Dialysis duration & +0.213 & 11.02 & 0.16 & $<0.001$ \\
\hline social support & +0.230 & 12.12 & 0.21 & $<0.001$ \\
\hline Subjective-well being & -0.172 & 3.21 & 0.044 & 0.013 \\
\hline Gender & +0.271 & 1.01 & 0.013 & 0.023 \\
\hline Hemoglobin & +0.320 & 11.03 & 0.23 & $<0.001$ \\
\hline
\end{tabular}




\section{Discussion}

The present empirical investigation has rigorously assessed the contribution of life-orientation, optimism and subjective well-being in determining perceived quality of life in patients with end stage renal disease. There have been numerous clinical studies in Pakistan that have explored end stage renal disease but none of the investigation ever taken such large sample size or tried to establish the predictors of better quality of life in ESRD. Thus current research endeavour has systematically highlighted the factors that can plausibly contribute in the domain perceived health related quality of life of patients with end stage renal disease. ESRD carries serious repercussions because even its treatment poses several co morbid complicated states.

The transitive phenomenon of coping with the end stage renal disease and making procedural adjustment to its treatment can create adversity for the client which could ultimately impair its health related quality of life. ${ }^{22,}{ }^{23}$ Still clinical pictures reveal that making adjustment to chronic states is dramatically different for different individuals. The main findings of the current investigation reveal that optimism, social support and subjective well-being especially the psychological component are significant predictors of perceived health related quality of life. The findings from this study enlighten us that the patients in end stage renal disease can enjoy better quality of life if they are provided with adequate social support, and they are given psycho education. The pertaining to importance of having optimism during management of end stage renal disease. There have been several researches that have supported these findings with reference to other chronic conditions such as AIDS and cancer. These investigations contribute thorough understanding into current research findings as this is reflected that positive approach permeated with optimism and social support is likely to improve our physical components and mental components of quality of life. ${ }^{24,25}$

One finding from main regression model also revealed that disease severity predicted the perceived quality of life of patients in end stage renal disease. There have been multifarious studies revealing that there is progressive association between quality of life and disease severity. ${ }^{26}$ Researchers have shown that HQoL impairs as the disease severity increases and there are series of complications that incept with passage of time. ${ }^{25}$ There are also incidences that due to marked deterioration in kidney functions, there could arise several complications. During this investigation, it was argued that the knowledge of having the disease or being labeled could also impact HR-QoL.

In this investigation, life orientation had been taken as a trait-like predisposition. This tendency to take life events in optimistic spirits may sometimes be shown as an outcome of past life events. In fact the past experiences carry the potential of determining an individual's evaluations and future aspirations. Optimism is significant positive predictor of improving the patients' capacity to overcome the challenges associated with disease and its management modalities. Seligman in this context had elaborated that an individual perceives and attends to life challenges better due to positive outlook in life. Associating better expectations in the spirit of optimism in itself proves rewarding as this helps in improving the feeling of wellbeing which further contributes in determining better quality of life in patients with end stage renal disease. ${ }^{27,28}$

Quality of Life in patients with end stage renal disease exist as coping strategy and as an indication of their physical and psychological smooth functioning. Its relationships with subjective wellbeing are well-established with reference to other chronic disease conditions. ${ }^{29}$ Personal characteristics of the recipients contribute effectively in determining the health related quality of life in spite of similar physical health status with so many others. Previous researches examining the relationship between optimism and subjective well-being have shown that optimism in patients with end-stage renal disease is significantly and positively related to life satisfaction and perceived quality of life. Lin, Chiang and Liu also indicated in their research findings that maintaining positive outlook can affect HR-QoL and subjective wellbeing. ${ }^{30,31}$

\section{Conclusion}

The present study highlighted the significance of lifeorientation especially optimism, social support and subjective well-being as significantly predicting the health related quality of life

in patients with end stage renal disease. In a developing country like Pakistan, people live with issues of limited resources without any health beneficent support by the government. Recipients with a satisfied QoL tend to be more optimistic instead of optimism improving perceptions with end stage renal disease can have better QoL if they hold optimism, social support and subjective well-being in form of life satisfaction. This invokes the active role of psychologists who can provide health counseling 
and can execute psycho-education services for improving the wellbeing and Quality of life of patients with end stage renal disease. Psychological Therapeutic interventions can effectively ensure the reduction of the gap between a person's present QoL and their enhanced well-being. By focusing more on current level of functioning, the recipients' analysis of optimism can be promoted which could ultimately change the way patients of end stage renal disease can gain insights into context of their lives. The positive approach towards the process of acceptance, adaptation and coping, amalgamated with adequate social support can ensure the better quality of life of patients with end stage renal disease. The strengths of this study lie in linking up the physical aspects of the disease with psychological and social aspects and finding efficacious benefits out of them.

Conflict of interest: None

\section{$\underline{\text { References }}$}

1. Levey disease.

$$
\text { AS, Coresh }
$$

Lancet.

J.

$$
\text { Chronic kidney }
$$
2012;379:165-180.

doi: $10.1016 / \mathrm{S} 0140-6736(11) 60178-5$. https://doi.org/10.1016/S0140-6736(11)60178-5

2. 2. Ministry of Health, Malaysia. Management of chronic kidney disease in adults, 2011. Retrieved from http://www.moh.gov.my

3. 3. Zhang QL, Rothenbacher D. Prevalence of chronic kidney disease in population-based studies: systematic review. BMC Public Health. 2008;8:117. doi: 10.1186/1471-2458-8-117. https://doi.org/10.1186/1471-2458-8-117

4. 4. Hooi LS, Ong LM, Ahmad G, Bavanandan S, Ahmad AN, Naidu BM, Mohamud WN, Yusoff MF. A populationbased study measuring the prevalence of chronic kidney disease among adults in West Malaysia. Kidney Int. 2013;84:1034-1040. doi: 10.1038/ki.2013.220. https://doi.org/10.1038/ki.2013.220

5. 5. Poppe C, Crombez G, Hanoulle I, Vogelaers D, Petrovic M. Improving quality of life in patients with chronic kidney disease: influence of acceptance and personality. Nephrol Dial Transplant. 2013;28(1):116-121. doi: 10.1093/ndt/gfs 151. https://doi.org/10.1093/ndt/gfs151

6. 6. Go AS, Chertow GM, Fan D, McCulloch $\mathrm{CE}$, Hsu C. Chronic kidney disease and risks of death, cardiovascular events and hospitalization. N Eng J Med. 2004;351:1296-1305. https://doi.org/10.1056/NEJMoa041031

7. 7. Tsai YC, Hung CC, Hwang SJ, Wang SL, Hsiao SM, Lin MY, et al. Quality of life predicts risks of end-stage renal disease and mortality in patients with chronic kidney disease. Nephrol Dial Transplant. 2010;25:1621-1626. doi: 10.1093/ndt/gfp671 https://doi.org/10.1093/ndt/gfp671 
8. Valderrábano F, Jofre R, Lopez-Gomez JM. Quality of life in end-stage renal disease patients. Am J Kidney Dis. 2001;38(3):443-464. https://doi.org/10.1053/ajkd.2001.26824

9. Wasserfallen JB, Halabi G, Saudan P, Perneger T, Feldman HI, Martin PY, et al. Quality of life on chronic dialysis: comparison between haemodialysis and peritoneal dialysis. NephrolDialTransplant.2004;19(6):1549-1599. https://doi.org/10.1093/ndt/gfh175

10. Perlman RL, Kiser M, Finkelstein F, Eisele G, Roys E, Liu L, et al. The longitudinal chronic kidney disease study: a prospective cohort study of predialysis renal failure. Semin Dialysis. 2003;16(6):418-423. https://doi.org/10.1046/j.1525-139X.2003.16093.x

11. Awuah KT, Finkelstein SH, Finkelstein FO. Quality of life of chronic kidney disease patients in developing countries. Kidney Int Supp. 2013;3:227-229. https://doi.org/10.1038/kisup.2013.20

12. PagelsAA, SoderkvistBK, Medin C, HylanderB, HeiweS. Health-related quality of life in different stages of chronic kidney disease and at initiation of dialysis treatment. Health and Qual Life Outcomes. 2012;10(1):71-71. https://doi.org/10.1186/1477-7525-10-71

13. Poppe C, Crombez G, Hanoulle I, Vogelaers D, Petrovic M Improving quality of life in patients with chronic kidney disease: influence of acceptance and personality. Nephrol Dial Transplant. 2013;28:116-121. doi: 10.1093/ndt/gfs151. https://doi.org/10.1093/ndt/gfs151

14. Soni RK, Weisbord SD, Unruh ML. Health-related quality of life outcomes in chronic kidney disease. Curr Opin Nephrol Hypertens. 2010;19(2):153159. doi:10.1097/MNH.0b013e328335f939. https://doi.org/10.1097/MNH.0b013e328335f939

15. Cruz MC, Andrade C, Urrutia M, Draibe S, NogueiraMartins LA, Sesso Ricardo de Castro Cintra. Quality of life in patients with chronic kidney disease. Clinics (São Paulo, Brazil). 2011;66(6):991-995. https://doi.org/10.1590/S1807-59322011000600012

16. Mapes DL, Lopes AA, Satayathum S. Healthrelated quality of life as a predictor of mortality and hospitalization: The dialysis outcomes and practice patterns study(DOPPS).KidneyInt. 2003;64(1):339-349. https://doi.org/10.1046/j.1523-1755.2003.00072.x

17. Spiegel BMR, Melmed G, Robbins S, Esrailian E. Biomarkers and health-related quality of life in end-stage renal disease: Asystematic review. Clin JAm Soc Nephrol. 2008;3(6):1759-1768. doi: 10.2215/CJN.00820208 https://doi.org/10.2215/CJN.00820208

18. Goodwin R, Engstrom G. Personality and the perception of health in the general population. Psychol Med. 2002;32:325-332. https://doi.org/10.1017/S0033291701005104

19. Goodwin RD, Cox BJ, Clara I. Neuroticism and physical disorders among adults in the community: results from the National Comorbidity Survey. J Behav Med. 2006;29(3):229-238. https://doi.org/10.1007/s10865-006-9048-5

20. ChristensenA,Ehlers S. Psychological factors in end-stage renal disease: an emerging context for behavioral medicine research. J Consult Clin Psych. 2002;70(3):712-724. https://doi.org/10.1037/0022-006X.70.3.712

21. Cohen SD, Sharma T,Acquaviva K, Peterson RA, PatelSS, Kimmel PL. Social support and chronic kidney disease: an update. Adv Chronic Kidney D. 2007;14(4):335-344. https://doi.org/10.1053/j.ackd.2007.04.007

22. Patel SS, Peterson RA, Kimmel PL. Impact of social support on end-stage renal disease. Semin Dialysis. 2005;18(2):98-102. https://doi.org/10.1111/j.1525-139X.2005.18203.x

23. Untas A, Thumma J, Rascle N, Rayner H, Mapes D, Lopes AA, et al. The associations of social support an other psychosocial factors with mortality and quality of lie in the Dialysis outcomes and Practice Patterns Study. Clin J Am Soc Nephrol. 2011;6(1):142-152 doi: 10.2215/CJN.02340310. https://doi.org/10.2215/CJN.02340310

24. Plantiga LD, Fink NE, Harrington-Levey R, Finkelstein FO, Hebah $\mathrm{N}$, Powe NR, et al. Association of social support with outcomes in incident dialysis patients. Clin J Am Soc Nephrol. 2010;5(8):1480-1488. doi: 10.2215/CJN.01240210. https://doi.org/10.2215/CJN.01240210

25. World Health Organisation. Definition and diagnosis of diabetes mellitus and intermediate hyperglycaemia. Geneva: WHO Document Production Services, 2006.

26. Chobanian AV, Bakris GL, Black HR, Cushman WC, Green LA, Izzo JL Jr, et al. and the National High Blood Pressure Education Program Coordinating Committee. Seventh report of the joint national committee on prevention, detection, evaluation, and treatment of high blood pressure: the JNC 7 report. JAMA. 2003;42(6):2560-2572. https://doi.org/10.1001/jama.289.19.2560

27. Weening JJ, D'Agati VD, Schwartz MM, Seshan SV, Alpers CE, Appel GB, et al. Classification of glomerulonephritis in systemic lupus erythematosus revisited. Kidney Int. 2004;65:521-530. https://doi.org/10.1111/j.1523-1755.2004.00443.x

28. Sararaks S, Azman AB, Low LL, Rugayah B, Aziah AM, Hooi LN, et al. Validity and reliability of the SF-36: The Malaysian context. Med J Malaysia. 2005;60(2):163179.

29. Gosling SD, Rentfrow PJ, Swann JWB. A very brief measure of the Big-Five personality domains. J Res Pers. 2003;37:504-528. https://doi.org/10.1016/S0092-6566(03)00046-1

30. Ong $\mathrm{CH}$. Validity and reliability of the Big Five Personality Traits Scale in Malaysia. IJIAS. 2014;5(4):309-315.

31. Lin MH1, Chiang YJ, Li CL, Liu HE.The relationship between optimism and life satisfaction for patients waiting or not waiting for renal transplantation.Transplant Proc. 2010 Apr;42(3):7635. doi: 10.1016/j.transproceed.2010.03.030. https://doi.org/10.1016/j.transproceed.2010.03.030 